\title{
Short-term acceptability of a single-size diaphragm among couples in South Africa and Thailand
}

\author{
Patricia S Coffey, Maggie Kilbourne-Brook, Mags Beksinska, Earmporn Thongkrajai
}

\begin{abstract}
Background The SILCS diaphragm is a new, reusable, single-size cervical barrier device that is designed to offer the same barrier protection as a standard diaphragm with improved user acceptability.

Methods This non-randomised, non-blinded, nonsignificant risk, multi-site pilot study assessed the short-term acceptability of the SILCS diaphragm among women with no previous diaphragm experience. Sites in South Africa and Thailand recruited couples not at risk of pregnancy and at low risk of sexually transmitted infections. Couples used the SILCS diaphragm four times and provided feedback on the ease of handling, comfort, and sensation during sex. Data were collected via detailed product-use questionnaires, simple coital logs and gender-specific debriefing interviews.
\end{abstract}

Results A total of 41 couples completed the study, providing data from 164 product uses. The SILCS device fits women representing a range of diaphragm sizes, parity and body mass index. Women from both sites reported that the SILCS diaphragm was easy to use and provided good comfort and sensation in over $80 \%$ of all product uses. Men from both sites reported good comfort and sensation in over $60 \%$ of all product uses.

Conclusion The SILCS diaphragm appears to be acceptable to women and men in low-resource settings. These data suggest that the SILCS design should be tested in broader populations to assess effectiveness and acceptability.

Keywords acceptability, diaphragm, pilot study, South Africa, Thailand

J Fam Plann Reprod Health Care 2008; 34(4): 233-236 (Accepted 17 April 2008)

\section{Introduction}

Diaphragms have been used as contraceptives for more than 100 years. Although women in developed countries find the devices acceptable, ${ }^{1}$ it is commonly believed that diaphragms are not appropriate for women in developing countries. However, data from several studies indicate that diaphragms may be acceptable to women in low-resource settings. ${ }^{2-9}$ When asked, women indicate that they want options for contraceptive methods that are under their control, easy to use, free from side effects, and effective at protecting them from pregnancy and sexually transmitted infections (STIs). ${ }^{10}$

Diaphragms may have the potential to meet these needs, as they offer effective protection from pregnancy 11 and may protect from STIs that attack the cervix. ${ }^{12}$ Because standard diaphragms are provided in a range of sizes, however, they require fitting by a trained provider, which can complicate supply and provision in some settings.

Renewed interest in cervical barrier devices has led to the design of new devices 13,14 and research into the potential role of diaphragms for STI/HIV prevention. ${ }^{15}$ The SILCS diaphragm - a new, single-size device - is part of this effort. With funding from the United States Agency for International Development (USAID) through the

Program for Appropriate Technology in Health (PATH), Seattle, WA, USA

Patricia S Coffey, PhD, MPH, Program Officer

Maggie Kilbourne-Brook, BS, Program Officer

Reproductive Health and HIV Research Unit, Westridge

Medical Centre, Durban, South Africa

Mags Beksinska, BSc, MSc, Provincial Director

Department of Medical Surgical Nursing, Faculty of Nursing, Khon Kaen University, Khon Kaen, Thailand

Earmporn Thongkrajai, BSc, MA, Professor

Correspondence to: Dr Patricia S Coffey, Program for Appropriate Technology in Health (PATH), 1455 NW Leary Way, Seattle, WA 98107-5136, USA. E-mail: pcoffey@path.org

\begin{abstract}
Key message points
- The SILCS diaphragm - a new, single-size, cervical barrier device - fits women representing a range of standard diaphragm sizes, parity and body mass index.

- Women and men in low-resource settings, including women with no previous experience with diaphragms, reported that the SILCS diaphragm was acceptable and easy to use.

- Female and male partners reported that sexual intercourse while using the SILCS diaphragm was satisfactory.
\end{abstract}

Contraceptive Research and Development Program (CONRAD), the Program for Appropriate Technology in Health (PATH) developed the SILCS device to address the main limitations of traditional diaphragms. The SILCS diaphragm has an anatomically shaped rim with a gentle spring that allows it to fit a wide range of women (Figure 1). Its single-size design should simplify inventory logistics and fit procedures required for multiple sizes.

Over the past 10 years, women in multiple sites have evaluated more than 200 prototype designs to refine the SILCS product features. A Phase 1 postcoital testing and

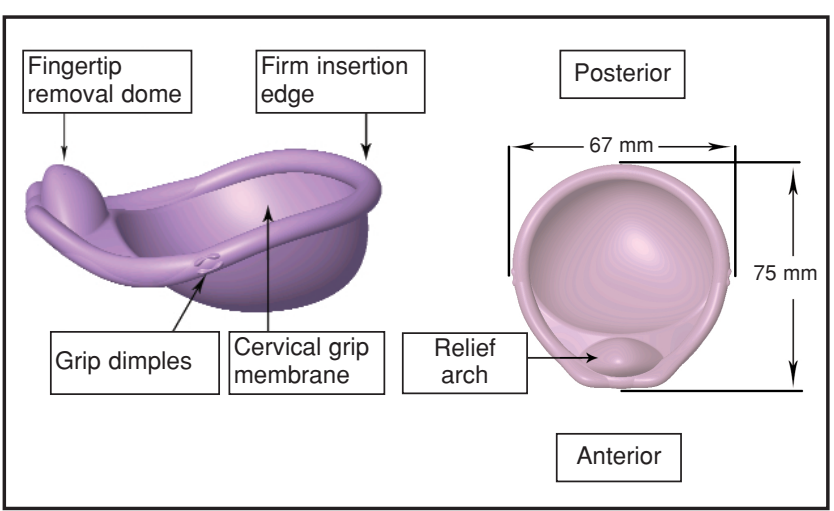

Figure 1 Diagrammatic representation of the SILCS diaphragm. (c) PATH. Figure reproduced courtesy of PATH 
Table 1 Characteristics of the female study participants

\begin{tabular}{lcc}
\hline Characteristic & $\begin{array}{c}\text { South Africa } \\
(\boldsymbol{n}=\mathbf{2 1}) \\
{[\boldsymbol{n}(\%)]}\end{array}$ & $\begin{array}{c}\text { Thailand } \\
(\boldsymbol{n}=\mathbf{2 0}) \\
{[\boldsymbol{n}(\%)]}\end{array}$ \\
\hline $\begin{array}{l}\text { Baseline diaphragm } \\
\text { size (mm) }\end{array}$ & \\
65 & $4(19)$ & $7(35)$ \\
70 & $11(52)$ & $13(65)$ \\
75 & $5(24)$ & 0 \\
80 & $1(5)$ & 0 \\
Parity & $4(19)$ & $1(5)$ \\
0 & $10(48)$ & $4(20)$ \\
1 & $6(29)$ & $13(65)$ \\
2 & $1(5)$ & $2(10)$ \\
$3-4$ & & \\
Body mass index & $8(38)$ & $9(45)$ \\
(BMI) (kg/m²) & $4(19)$ & $10(50)$ \\
Normal (18.5-24.9) & $9(43)$ & $1(5)$ \\
Overweight $(25-29.9)$ & 28.6 & 26.2 \\
Obese (30+) & & \\
Median BMI & & \\
\hline${ }^{*} p=0.006$. & &
\end{tabular}

safety study confirmed fit, acceptability and barrier effectiveness of the SILCS diaphragm among women in the USA. ${ }^{16}$ The SILCS device has not yet been approved for use by the United States Food and Drug Administration or any foreign regulatory agency.

The pilot acceptability study reported here was conducted to assess the fit of the SILCS diaphragm among women and its acceptability among couples with no previous diaphragm experience in two regionally distinct low-resource settings.

\section{Methods}

The study team recruited participants from family planning clinics in South Africa and Thailand. These locations are amenable to user-focused research and have populations that reflect different circumstances (e.g. rural vs urban). Women attending family planning clinics were informed of the study. Sites recruited women who represented a range of body sizes and parity status. Male and female partners were screened for study participation according to eligibility criteria. For this minimal-risk study, eligible women had to be using a non-barrier method of contraception (or one member of the couple had to be sterilised), test negative for a urine pregnancy test, and be free from STIs as determined by a pelvic examination and Pap smear. Couples had to be of legal age (18 years in South Africa and 20 years in Thailand) and report being in a mutually monogamous relationship for the previous 6 months, with plans to continue in the same relationship throughout the study.

Informed consent was obtained from women at the time of screening. If a woman passed the screening and enrolled in the study, informed consent was then obtained from her partner as well. In keeping with the local standards of counselling for dual protection, South African couples were counselled to consider concurrent male condom use during this study if they had any risk or concerns regarding STIs.

Study data were collected from February to July 2004. During the screening visit the clinician recorded the woman's height and weight for calculation of body mass index (BMI) using a standard formula (http://www.nhlbisupport.com/bmi). Women were fitted with an Ortho All-Flex ${ }^{\circledR}$ diaphragm to assess baseline size. The clinician provided written and verbal coaching about using the SILCS diaphragm. Each woman then practised inserting the device, checking fit and removing the device.
She was required to demonstrate correct insertion, placement and removal at least once before the clinician approved her to use the device at home. Women were shown how to clean the device and informed how to store it between uses. Women were instructed to wear the SILCS diaphragm at least 6 hours and no longer than 24 hours after sexual intercourse in accordance with standard diaphragm guidance. ${ }^{11}$ Women used a lubricant $\left(\mathrm{K}-\mathrm{Y}^{\circledR}\right.$ Jelly) rather than spermicide since the study was not evaluating the diaphragm's contraceptive effectiveness.

Couples were instructed to use the SILCS diaphragm once during sex and then return to the clinic within 72 hours to record their experiences. At the return visit, women demonstrated again that they could correctly insert and remove the diaphragm, and couples confirmed their interest in continuing in the study. They were then instructed to have sex while using the SILCS device three more times over a period of 2 weeks. Couples completed a simple coital log at home after the second and third product uses. After the first and fourth uses they returned to the clinic and separately completed detailed product-use questionnaires. After all four uses, each partner also participated in a gender-specific debriefing interview.

The coital log collected information about the woman's experience with insertion and removal of the device, concurrent use of a male condom, and both partners' experience with comfort and satisfaction while using the device. Response categories for the coital log were "good", "OK" or "bad" for all questions. Acceptability of the diaphragm was measured by means of the primary outcome variables of ease of use, user comfort, and sensation while using the device during sex. For the purpose of this evaluation, responses of "good" were considered acceptable.

Data were collected in local languages, translated into English, entered into Word templates, and transferred electronically to PATH for analysis using the Statistical Package for the Social Sciences (SPSS) version 12.0 (SPSS Inc., Chicago, IL, USA). Sample size was based on convenience, as is appropriate for an initial acceptability study of a new device. ${ }^{17-19}$ Univariate statistics and frequency distributions were employed for descriptive purposes. The Chi-square test was used to detect differences in demographic characteristics and acceptability indicators among users from South Africa and Thailand.

\section{Ethical approval}

The PATH Human Subjects Protection Committee, the Khon Kaen University Ethical Committee and the University of Witwatersrand Ethical Committee reviewed and approved the study protocol.

\section{Results}

A total of 41 women and their male partners enrolled in the study (Table 1). None of the women had previously used a diaphragm. All enrolled couples completed the protocol. There were a total of 164 product uses. No adverse events were reported, and no problems were noted with cleaning or storing the SILCS diaphragm.

Overall acceptability of the SILCS diaphragm among women and men was relatively good across both sites (Table 2). Significantly more women in South Africa reported that their insertion experience was "good" than did women in Thailand ( $\mathrm{p} \leq 0.001)$. Thai women's reported ease of inserting the SILCS device improved with experience, as women reported third product uses as "good" more often than second product uses (89\% vs 50\%, respectively). 
Table 2 Summary of acceptability indicators

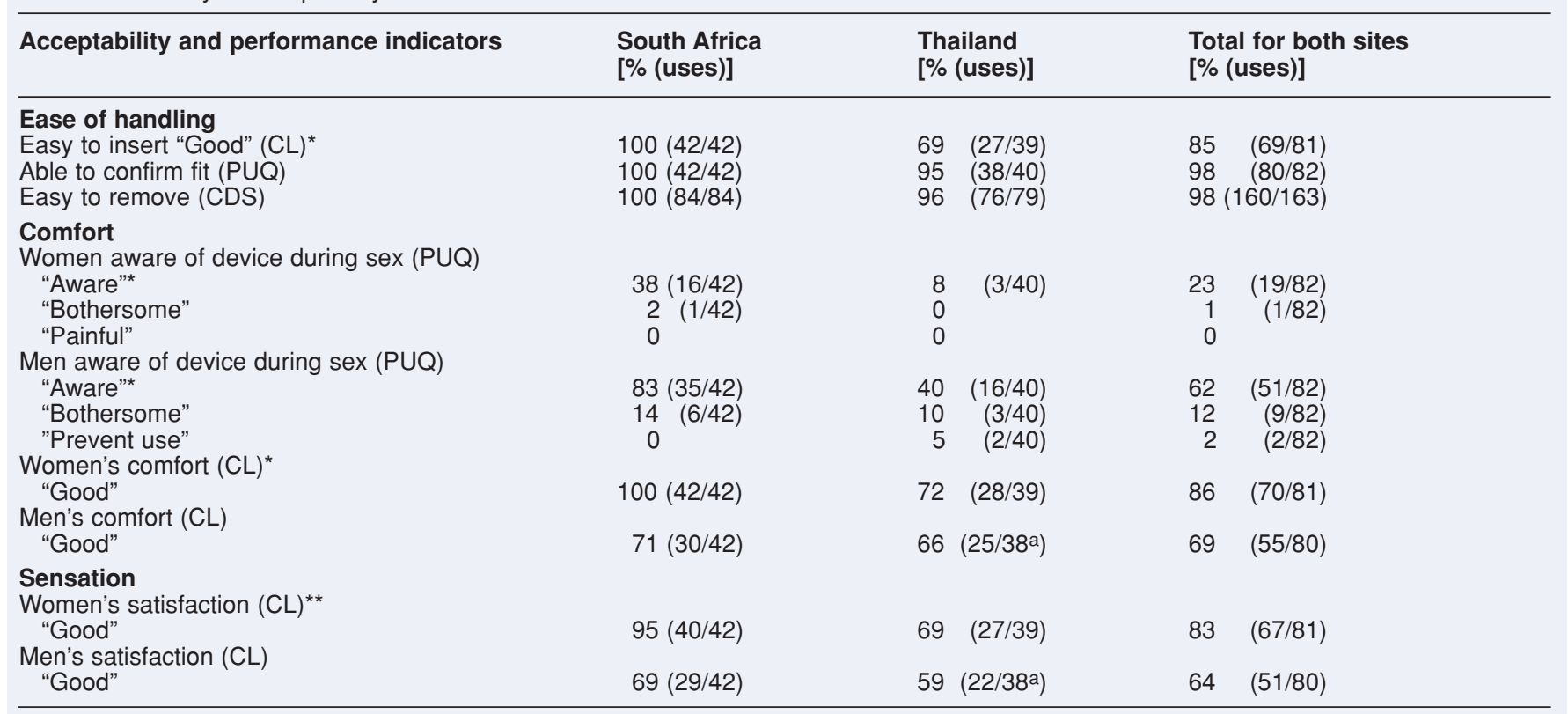

aData point missing on one Thai coital log. ${ }^{*} p \leq 0.001 ;{ }^{* *} p=0.005$.

CDS, combined dataset from both CL and PUQ representing four product uses ( $n=84$ for South Africa, $n=79$ for Thailand); $C L$, coital log data from second and third product use only ( $n=42$ for South Africa, $n=39$ for Thailand); PUQ, product use questionnaires data from first and fourth use only ( $n=42$ for South Africa, $n=40$ for Thailand).

All 21 women in South Africa and 19 women in Thailand reported being able to confirm fit and placement of the SILCS diaphragm. Women from both sites reported that the SILCS diaphragm was easy to remove during all four uses; none reported problems or discomfort during removal.

Women reported awareness of the SILCS device during sex in $23 \%$ of product uses overall. More South African women than Thai women reported awareness during sex $(\mathrm{p} \leq 0.001)$. None of the instances of awareness from Thailand and one of the instances of awareness from South Africa were described as "bothersome". No instances of awareness were characterised as "painful".

Men reported awareness of the SILCS during sex in $62 \%$ of product uses. More South African men than Thai men reported awareness during sex $(\mathrm{p} \leq 0.001)$. One Thai man reported the awareness as "bothersome" during both the first and fourth product use. He also reported that this awareness "would prevent future use" not because of "pain" but because it "took longer to reach orgasm".

Reported comfort by women and men in both sites was high during second and third product uses, although men reported marginally less comfort than did women overall $(p$ $=0.053)$. Thai women reported comfort as "good" during product use significantly less often than did women from South Africa $(p \leq 0.001)$. Men in both sites reported comfort as "good" during the majority of second and third product uses. In South Africa two men reported comfort as "bad" during one use each.

Women and men both reported similar levels of satisfaction with sensation of sex while using the SILCS diaphragm. Thai women reported sensation as "good" during use slightly less often than women from South Africa $(p=0.005)$. Men from both sites reported satisfaction during sex as "good" during the majority of product uses. All men from both sites reported being able to achieve orgasm during all first and fourth uses.

In Thailand, no couples reported concurrent use of a male condom with a SILCS diaphragm. In South Africa, 17 of the 21 couples used male condoms at least once, representing $50 \%$ of product uses; three couples used condoms with every product use. The couples that used condoms did not report any instances of displacement of the diaphragm during sex. Men's reported comfort and satisfaction during use with a condom compared to without a condom did not differ significantly during second and third uses. Awareness of the device was not significantly affected by condom use during first and fourth uses.

\section{Discussion}

This study was the first evaluation of the SILCS diaphragm in low-resource settings in communities with no previous experience with diaphragms. Women representing a range of baseline diaphragm sizes $(65-80 \mathrm{~mm})$, parity $(0-4)$ and BMI (18.5-44.7, or normal to obese) were all able to insert, check and use the SILCS device comfortably. Women and men from both South Africa and Thailand found the device acceptable during sex. These results suggest that women without previous diaphragm experience in communities where diaphragms are unavailable should be able to use the SILCS diaphragm successfully. This finding parallels reports of acceptability of standard diaphragms in other low-resource settings. ${ }^{2-9}$

The acceptability of the SILCS device among women was generally high across both groups. It is interesting to note that ease of insertion among Thai women, while acceptable at first, improved by the fourth use. Comfort was somewhat compromised for men at both sites due to contact with the cervical rim. Reports of feeling the device during sex, however, did not lead to negative sexual experiences for men in terms of comfort, satisfaction or ability to achieve orgasm.

Of particular interest is the satisfactory use of the SILCS device with a male condom, which did not appear to affect comfort, sensation or device stability. This confirms similar reports of successful diaphragm and male condom use during the Methods for Improving Reproductive Health in Africa (MIRA) study. ${ }^{15}$ This finding may allay concerns that diaphragm promotion in areas of high HIV prevalence would necessarily lead to condom migration and a resulting rise in HIV rates. ${ }^{20}$ It also bodes well for the implementation of dual-protection programmes using a contraceptive diaphragm. 
The study was limited by its small sample size; consequently, its power to detect satisfaction and comfort is also limited. Due to selection bias it is not clear if similar study results could be replicated in the general population. In addition, recruitment of women from family planning clinic populations may bias results towards those who are already willing to use a contraceptive method. However, the favourable results point toward the acceptance of this product, especially among couples in stable partnerships that value the benefits of female barrier contraception.

A contraceptive effectiveness study evaluating use of the SILCS diaphragm with contraceptive gel is currently underway in the USA with the results expected in 2010. Additional research evaluating service delivery options for a single-size cervical barrier device would also help clarify the feasibility of adding the SILCS diaphragm to reproductive health programmes worldwide.

\section{Acknowledgements}

PATH would like to acknowledge the effort and commitment of their research partners in South Africa and Thailand, the women and men who willingly shared their experiences, and the collaborative research partnership with CONRAD, which has supported design development and evaluation of the SILCS diaphragm since 1994.

\section{Statements on funding and competing interests}

Funding This study was supported by CONRAD, Eastern Virginia Medical School, under USAID Cooperative Agreement \#HRN-A00-98-00020-00, and the Bill \& Melinda Gates Foundation. The opinions expressed herein are those of the authors and do not necessarily reflect the views of USAID, CONRAD or the Bill \& Melinda Gates Foundation.

Competing interests PATH designed the SILCS diaphragm with funding from USAID through the CONRAD Program.

\section{References}

1 Maher JE, Harvey MS, Thorburn Bird S, Stevens VJ, Beckman LJ. Acceptability of the vaginal diaphragm among current users. Perspect Sex Reprod Health 2004; 36: 64-71.

2 Behets F, Norris Turner A, Van Damme K, Rabenja NL, Ravelomanana N, Zeller K, Rasolofomanana JR. Acceptability and feasibility of continuous diaphragm use among sex workers in Madagascar. Sex Transm Infect 2005; 81: 472-476.

3 Bulut A, Ortayli N, Ringheim K, Cottingham J, Farley TM, Peregoudov $\mathrm{A}$, et al. Assessing the acceptability, service delivery requirements, and use-effectiveness of the diaphragm in Colombia, Philippines, and Turkey. Contraception 2001; 63: 267-275.

4 Ortayli N, Bulut A, Nalbant $\mathrm{H}$, Cottingham J. Is the diaphragm a viable option for women in Turkey? Int Fam Plann Perspect 2000; 26: 36-42.

5 Sundari Ravindran TK, Rao SS. Is the diaphragm a suitable method of contraception for low-income women: a users' perspectives study, Madras, India. In: Beyond Acceptability:
Users' Perceptions on Contraception. London, UK: Reproductive Health Matters for the World Health Organization, 1997.

6 Di Giacomo Lago T, Barbosa RM, Kalckmann S, Vieira Villela W, Gohiman S. Acceptability of the diaphragm among lowincome women in Sao Paulo, Brazil. Int Fam Plann Perspect 1995; 21: 114-118.

7 van der Straten A, Kang MS, Posner SF, Kamba M, Chipato T, Padian NS. Predictors of diaphragm use as a potential sexually transmitted disease/HIV prevention method in Zimbabwe. Sex Transm Dis 2005; 32: 64-71.

8 Ellertson E, Burns M. Reexamining the role of cervical barrier devices. Outlook 2003; 20: 1-8.

9 Luchters S, Chersich MF, Irene J, Schroth A, Chidagaya S, Mandaliya $\mathrm{K}$, et al. Acceptability of the diaphragm in Mombasa Kenya; a 6-month prospective study. Eur J Contracept Reprod Health Care 2007; 12: 345-353.

10 Sundari Ravindran TK, Berer M, Cottingham J (eds). Beyond Acceptability: Users' Perspectives on Contraception. London, UK: Reproductive Health Matters for the World Health Organization, 1997.

11 World Health Organization Department of Reproductive Health and Research (WHO/RHR) and Johns Hopkins Bloomberg School of Public Health/Center for Communication Programs (CCP), INFO Project. Family Planning: A Global Handbook for Providers. Baltimore, MD and Geneva, Switzerland: CCP and WHO, 2007.

12 Moench TR, Chipato T, Padian NS. Preventing disease by protecting the cervix: the unexplored promise of internal vaginal barrier devices. AIDS 2001; 15: 1595-1602.

13 Mauck CK, Weiner DH, Creinin MD, Archer DF, Schwartz JL, Pymar HC, et al. FemCap with removal strap: ease of removal, safety, and acceptability. Contraception 2006; 73: 59-64.

14 Mauck CK, Creinin MD, Rountree W, Callahan NM, Hillier SL. Lea's Shield: colposcopic and microbiological testing during 8 weeks of use. Contraception 2005; 72: 53-59.

15 Padian NS, van der Straten A, Ramjee G, Chipato T, de Bruyn G, Blanchard K, et al.; MIRA Team. Diaphragm and lubricant gel for prevention of HIV acquisition in southern African women: a randomised controlled trial. Lancet 2007; 370: 251-261.

16 Schwartz J, Mauck C, Rountree RW, Ballagh S, Creinin M, Kilbourne-Brook M. SILCS diaphragm: postcoital testing of a new, single size contraceptive diaphragm. Obstet Gynecol 2006; 107(4 Suppl.): 12S

17 Ballagh SA, Brache V, Mauck C, Callahan NM, Cochon L, Wheeless A, et al. A Phase I study of the functional performance, safety, and acceptability of the BufferGel ${ }^{\circledR}$ Duet $^{\mathrm{TM}}$. Contraception 2008; 77: 130-137.

18 Roizen J, Richardson S, Tripp J, Hardwicke H, Lam TQ. Oves contraceptive cap: short-term acceptability, aspects of use and user satisfaction. J Fam Plann Reprod Health Care 2002; 28: 188-192.

19 Bounds W, Guillebaud J. Lea's Shield contraceptive device: pilot study of its short-term patient acceptability and aspects of use. Br J Fam Plann 1999; 24: 117-120.

20 Posner S, van der Straten A, Kang M, Padian N, Chipato T. Introducing diaphragms into the mix: what happens to male condom use patterns? AIDS Behav 2005; 9: 443-449.

\section{BOOK REVIEW}

The New Joy of Sex. Alex Comfort, Susan Quilliam. London, UK: Mitchell Beazley, 2008. ISBN-13: 978-1-84533-429-1. Price: £18.99. Pages: 288 (paperback)

Readers of a certain age will remember the publication of the original Joy of Sex - a book ahead of its time in the 1970s. Highly graphical with clear explicit information, it was updated in the 1990s, and it now has been fully revised, updated and refocused to meet the needs of women and men in today's contemporary world. Alex Comfort, the doyen of sex, was committed to providing good information to "undo some of the mischief caused by the guilt, misinformation and no-information". He believed strongly about "the central importance of unanxious, responsible, and happy sexuality in the lives of normal people". These beliefs are wholly shared by the co-author of this 2008 edition, Susan Quilliam, who is an extremely well-known relationships psychologist and sexologist. Although we are now in the $21 \mathrm{~s}$ century, myth, misinformation and guilt still surround issues to do with sex, the prevalence of sexual ignorance and problems is high and, sadly, access to good help, understanding and support remains low. This book does deliver what it says on the cover - it addresses the joys of sex to enable couples to find out more about themselves, their desires and their needs. This is not a book about 'basics' but it does address the fundamenta building blocks required for good sexual relationships - an understanding of reproductive anatomy and physiology, compatibility, love, fidelity, age and health. It addresses seduction, lovemaking, intercourse, non-intercourse sex, safer sex, sexual techniques, experimentation, the use of erotica, sex toys and brings in technology such as use of e-mail, text, phone sex and the Internet. Whilst The New Joy of Sex is written for couples to enable them to get more out of their sexual lovemaking, the text in parts is cleverly interspersed with 'tips from him to her' and vice versa, and the information contained in this book would be of value to anyone who reads it. Do I have any quibbles with this book? The information content is excellent, but in today's contemporary world, where we all come in different shapes, size, age and colour - this book's photographs and diagrams with their perfect (almost hairless, wrinkle-free) young, white women and men does not reflect this. The resource section is helpful but rather short and omits important organisations such as Cancerbackup and The Institute of Psychosexual Medicine.

Reviewed by Toni Belfield, BSc, Hon FFSRH Specialist in Sexual and Reproductive Health Information, UK 